\title{
How Does the Stock Market Respond to Chemical Disasters?*
}

\author{
Gunther Capelle-Blancard ${ }^{\dagger}$ and Marie-Aude Laguna ${ }^{\ddagger}$
}

This version: June 2009

\footnotetext{
*Financial support from the French Ministry of Ecology and Sustainable Development is gratefully acknowledged. Marie-Aude Laguna also benefited from the support of the "Fédération Bancaire Française Chair in Corporate Finance". We thank Thierry Chauveau, Frédéric Jouneau-Sion, Paul Lanoie, Sandrine Lardic, Stéphanie Monjon, Pierre Morin, Georges Prat, Alessandro Riboni, Bernard Sinclair-Desgagné, Sandrine Spaeter and Andreas Ziegler for helpful comments, as well as participants at the University of Nantes and University of Paris I seminars, AFFI International Conference 2005, the Second Toulouse-Montreal Conference on the Law, Economics and Management of Larges-Scale Technological Risks 2005, and the 2006 European Economic Association Annual Congress, and Richard Jonathan for editorial assistance. We especially thank Arik Levinson and two anonymous referees for helpful comments. This paper was written while Marie-Aude Laguna was a graduate student at the Université Paris I Panthéon-Sorbonne and a fellow at the Agence de l'Environnement et de la Maîtrise de l'Energie. The usual disclaimer applies.

${ }^{\dagger}$ Université Paris 1 Panthéon-Sorbonne. 106-112 bd de l'hôpital 75013 Paris, France, Tel: +33 144078270. Email: gunther.capelle-blancard@univ-paris1.fr.

${ }^{\ddagger}$ Université Paris-Dauphine, DRM, F-75016 Paris, France, Tel: +33 144054 257, Fax: +33 144054023. Email: marie-aude.laguna@univ-paris1.fr Corresponding author.
} 


\title{
How Does the Stock Market Respond to Chemical Disasters?
}

\begin{abstract}
In this paper, we examine the stock market reaction to industrial disasters. We consider an original sample of 64 explosions in chemical plants and refineries worldwide over the period 1990-2005. A quarter of the accidents resulted in a toxic release, and half of them caused at least one death or serious injury. On average, petrochemical firms in our sample experience a drop in their market value of $1.3 \%$ over the two days immediately following the disaster. Using multivariate analysis, we show that this loss is significantly related to the seriousness of the accident as measured by the number of casualties and by chemical pollution: each casualty corresponds to a loss of $\$ 164$ million and a toxic release to a loss of $\$ 1$ billion.
\end{abstract}

JEL Classification: G14, Q27, Q51.

Keywords: Technological Risk, Event Study, Environmental Liability, Disclosure, Insurance. 


\section{Introduction}

Chemical disasters are one of the major technological risks that modern societies face. Such accidents directly affect firms' revenues by disrupting their production process, but they also generate negative externalities on health and ecosystems. Catastrophes like the explosion in Seveso (Italy) in 1976, the release of toxic gas in Bhopal (India) in 1984, or the explosion of a BP refinery in Texas (US) in 2005 clearly illustrate the enormous risk potential of petrochemical plants. These catastrophic accidents were very well publicized, but they are only the visible part of the iceberg. According to the U.S. Environmental Protection Agency, $8 \%$ of the petrochemical facilities in the US reported at least one accident over the period 1994-2000. The total number of accidents during that period was nearly 2,000 and half of them caused employee or public injuries ( [10]). In the European Union, between 1971 and 2005, there were about 30 industrial accidents that each resulted in 25 or more fatalities. ${ }^{1}$

In this paper, we examine the stock market's reaction to chemical disasters from 1990 to 2005. This subject is particularly relevant because many scholars have suggested (see, for example, [37]; [7]) that the threat of a severe market penalty can complement government regulation by providing incentives to comply with safety and environmental standards and/or to innovate in order to prevent accidents. To carry out our analysis, we build an original sample of the 64 explosions in chemical plants and refineries that occurred worldwide from 1990 to 2005. The software program Factiva (which covers more than 10,000 news sources) was used to search in a systematic way for the press articles mentioning publicly traded companies responsible for disasters. Also, this search allowed us to build a number of useful variables measuring the social consequences of each disaster, such as their effect on health and on the environment.

A few studies, similar to us, have examined the financial implications of industrial disasters with environmental consequences. [26] and [34] consider relatively small samples of pollution 
accidents in the U.S. in the late 1980s and early 1990s. In their analysis, pollution accidents are associated with a significant drop in stock returns. In contrast, Jones and Rubin (2001) do not find significant results by looking at a sample of 14 accidents that occurred in the oil and power sector between 1970 and 1992. Finally, a number of case studies have investigated the stock market response to catastrophes such as the Exxon-Valdez oil spill and the Bhopal chemical explosion (e.g., [18]; and [35]). ${ }^{2}$ Their results indicate that in the first month following those two major accidents, abnormal losses range between -12\% (for the Exxon-Valdez oil spill) and $-30 \%$ (for the Bhopal explosion). ${ }^{3}$ Another strand of literature has examined the stock market response to the publication of the U.S. Toxic Release Inventory (TRI), a publicly available database that contains information on toxic chemical releases and waste management activities reported annually by industries ( [15]; [27]; [25]). The seminal paper of [15] shows that the average stock market loss over six days following the publication of the U.S. TRI in 1989 is equal to $1.20 \%$. Several studies have investigated the consequences of judicial actions for environmental violations on stock market value in the U.S. ${ }^{4}$ Finally, [9] study the average stock market drop following violations of existing Korean environmental laws and regulations. Interestingly, they confirm previous evidence that stock market penalties are much higher in developing countries ( [8]; [14]).

One contribution of this paper is to analyze the financial consequences of industrial disasters and the determinants of the investor reaction over a longer (and more recent) time span, and to do so for various countries. Investigating the stock market response to recent industrial accidents is of particular interest, since new regulations aimed at preventing such disasters and improving firm transparency have been introduced. Moreover, it is equally interesting to study cross-country samples because one can speculate that differences in regulation across countries influence stock market response.

In the first part of the econometric analysis, we assess the average market value losses in- 
curred by shareholders using an event-study methodology. We expect investors to react to a disaster because many costs, such as liabilities for personal injuries or environmental penalties, are uninsured or barely insurable. Moreover, after an accident, stakeholders are likely to modify their belief about the safety of that particular plant or of the firm as whole. This may lead to an increase in insurance premiums, the expectation of tighter government regulation, or the worsening of relations with customers, employees, suppliers and investors. Our results indicate that firms do incur a financial loss after a chemical disaster. On an accident-by-accident basis, statistical significance is difficult to detect because of the volatility in firms'stock returns. Three out of four accidents in our sample are associated with negative abnormal returns, but the losses are statistically significant for only one-fourth of the accidents. At the same time, we are able to draw conclusions about the overall significance of our results. On average, cumulative abnormal returns are significantly different from zero and amount to $1.3 \%$ over the two days immediately following the accident.

In the second part of the econometric analysis, we attempt to explain the determinants of the drop in market value incurred by each firm using multivariate regression analysis. We find that the number of fatalities and serious injuries as well as the occurrence of pollution significantly aggravate the magnitude of the decrease in the first days after the accident. We also provide estimates of the market loss associated with each fatality and with the occurrence of pollution: one fatality or serious injury causes an additional loss of approximately $\$ 164$ million, whereas a toxic release corresponds to an average loss between $\$ 190$ million and $\$ 1.82$ billion. This large confidence interval is not surprising, given that, due to a lack of available information, we use a dummy which controls for the occurrence of a toxic release, but not for its severity. Finally, we also document that, over six months after the accident, a toxic release represents an additional loss of $12 \%$ (statistically significant at the $5 \%$ level). This result may follow from a delayed reaction (that is, stock markets do not fully and immediately incorporate the losses) and/or a 
premium due to an increase of the perceived riskiness of the firm.

\section{The data}

\subsection{The sample of accidents}

The aim of this paper is to provide robust empirical evidence on the stock market reaction to chemical disasters. Unfortunately, there is no global, publicly available list of the major chemical disasters that disclose the names of companies responsible for disasters. ${ }^{5}$ To identify the chemical disasters, we compiled a corpus of print media articles for the period 1990-2005.

A systematic search using the software Factiva was carried out. This software covers all major newspapers and publications in the world (including major publications such as The Wall Street Journal or The Financial Times). We selected all news stories written in English (over 10,000). The search was carried out using two keywords: "explosion" and "chemical plant", and excludes all accidents reported by newspapers before 1990 and after 2005. Using the two keywords, we started with about 200 events. Of these, two-thirds were eliminated because they did not involve publicly traded companies (they concerned state-owned companies, illegal factories, etc.). Datastream, which covers more than $75 \%$ of publicly listed companies in the world, was used to identify a sample of 38 publicly traded companies responsible for 64 accidents. The list of accidents and a brief description is presented in the Table 2. The firms are listed on the stock markets of ten developed countries (Australia, France, Germany, Japan, Netherlands, Norway, Spain, Switzerland, United Kingdom, the United States) and two emerging countries (South Africa and South Korea). 


\subsection{The features of accidents}

The distinctive characteristics of accidents are also drawn from print media. We consider indirect speeches by local populations, public authorities, unions and company spokespersons, environmental interest groups, citizens' groups, fire brigades, the police, etc., as reported in newspaper articles. Table 3 reports some descriptive statistics.

Human harm. This variable measures the number of injured that were listed as "in serious condition" and the number of fatalities due to the accident. More than half of the accidents resulted in at least one fatality and a serious injury. The average number of fatalities and serious injuries is 2.6.

Pollution. This variable is measured by a dummy set equal to one if we have information that the accident resulted in a toxic release. Chemical releases are classified as toxic on the basis of the statements issued by the authorities, environmentalist groups, and the companies themselves. For instance, the authorities state that "no dangerous chemicals were released into the air" (March 1992, Dow Chemical); or that "more than 10 tons of poisonous chemicals were released" (February 1993, Hoescht). In one quarter of the accidents, the chemical release was toxic enough to contaminate the environment. ${ }^{6}$

Reputation. The firm reputation is measured by the number of similar accidents previously experienced by each firm since $1980 .{ }^{7}$ In the absence of perfect information, an accident constitutes an informative signal that investors use to infer the environmental riskiness of each firm. Thus, stock market response should depend on the current accident but also on the previous safety and environmental records of firms.

Size. The firm size is measured by the log of its market value (in 2005 US\$) on the day before the accident. In percentage terms, the effect of an equally sized accident on the stock market value should be lower for big firms. The impact of an accident in a small firm might also 
be more severe because shares of small firms are less liquid and because small firms do not have the same opportunity as big firms to reallocate their production across plants in order to fulfill their contracts in the event of an accident.

Abnormal Media Coverage. This variable is obtained by computing the ratio between the number of headlines that mention the firm in the twenty days before a disaster and the total number of headlines received in the previous year. This variable is meant to capture the visibility of the firm at the time of the incident. Using the ratio should control for the fact that some firms are more present in the media. This variable is equal to $5.5 \%$ on average, and varies between 0 and $20 \%$. The visibility of the firm may have an effect on stock returns through various channels. It might increase the number of informed investors about the disaster. It could also proxy for other news announcements and confounding effects at the time of disasters, which may crowd out the effect of accident news on stock markets. We also use a dummy variable set equal to one if the accident was mentioned in either The Wall Street Journal or The Financial Times.

Oil versus Chemical Sector. A dummy is set equal to one if the company belongs to the chemical sector and zero if it belongs to the oil sector. In our sample, $68 \%$ of accidents are caused by chemical firms.

Time. Accidents appear uniformly distributed over the period 1990-2005. Two five-year dummy variables are used for accidents that occurred between 1995 and 1999, and for accidents that occurred between 2000 and 2005. The effect of time is difficult to predict. On the one hand, since in most developed countries transparency has increased, accidents might have a lower informational content. ${ }^{8}$ On the other hand, public concern about pollution might aggravate stock market losses due to reputation damage and legal implications.

Countries. Four dummy variables are introduced to control for accidents that occurred in the United Kingdom, in continental Europe, in Japan and in emerging countries (the reference variable corresponds to accidents that occurred in North-America). ${ }^{9}$ We expect structural dif- 
ferences between countries to be relevant due to differences in environmental liability rules, in the stringency of regulation (see [16]), and in legal origin (see [30]).

\section{Equity returns losses following chemical disasters}

We expect stock market value to decrease for numerous reasons. The most obvious costs of an accident consist in damage to fixed assets (including property), loss of inventory, raw materials and finished products, and business interruption. As firms carry insurance against most of these losses, the decline in firm value should be mainly related to costs that are barely insurable, such as liabilities for personal injuries or environmental penalties. ${ }^{10}$ Moreover, accidents represent a signal about the riskiness of a firm. After an accident, stakeholder and investors update their belief about the safety of that particular plant or of the entire firm. Consequently, market capitalization can be affected by portfolio rebalancing. Insurance companies may increase insurance premiums and require more stringent safety standards; public authorities may reinforce the regulations and thereby raise the cost of regulatory compliance for firms; customers and suppliers may move away from firms; analysts and investors may view the earnings of firms riskier than previously expected. Finally, firms will have to spend on advertising in order to improve their public image.

In this section, we provide evidence of average equity value losses, both in the short-term and in the long-term. After presenting our results, subsection 3.4 relates our findings to the ones obtained by previous literature.

\subsection{The event study methodology}

To examine stock price behavior related to explosions in petrochemical plants, we performed a daily event study as implemented by [31]. The change in equity value associated with an explosion 
in a petrochemical plant is taken as an unbiased estimate of the total financial consequences of the accident (all expected uninsured future costs). ${ }^{11}$

The market model is applied to describe the behavior of asset returns and to separate out changes in value caused by overall market effects from those changes caused by the accident itself. The normal relation between the observed returns of a given stock $i$ at time $t, R_{i, t}$, and the market returns at the same time, $R_{m, t}$, is given by: $R_{i, t}=\alpha_{i}+\beta_{i} R_{m, t}+\varepsilon_{i, t}$. The term $\beta_{i} R_{m, t}$ is the portion of the return to security $i$ on day $t$ that is due to marketwide factors. The parameter $\alpha_{i}$ measures that part of the average daily return on the stock that is not due to market movements. Lastly, $\varepsilon_{i, t}$ measures that part of the change in the value of firm's $i$ stock on day $t$ that is not due to either movements in the market or to the firm's average daily return. On the day of an event (here the explosion in a chemical plant or in an oil refinery), the deviation in an individual stock's daily return from what is expected based on the previous equation, that is, the prediction error, is taken as an unbiased estimate of the financial effects of the event. Let $A R_{i, t}=R_{i}-\widehat{\alpha_{i}}-\widehat{\beta}_{i} R_{m, t}$ stand for this abnormal return or prediction error where $\widehat{\alpha_{i}}$ and $\widehat{\beta_{i}}$ are respectively, the estimates of $\alpha_{i}$ and $\beta_{i} \cdot{ }^{12}$ Abnormal returns are computed given the market model parameters estimated with OLS through the period [-190; -10] in event time. Event time is days relative to the accident date.

Following [31], we calculate an individual t-statistic for each firm's abnormal return for each accident-day. Moreover, the average abnormal daily return for all accidents in the sample, $A A R_{t}$, is calculated along with its statistical significance. The sum of the individual t-statistics follows a distribution that is asymptotically normal with mean zero and variance equal to the number of observations. The z-statistic for the average is then the sum of the individual t-statistics divided by the square root of the number of observations. ${ }^{13}$ To examine the average loss incurred by shareholders, we also look at the cumulative average abnormal returns since the accident date, $C A A R_{t}$ ( [31]). Finally, we compute the average abnormal shareholder loss $\left(S L_{t}\right)$ due to the 
chemical explosions by multiplying the market value on the day before the accident with the cumulated abnormal returns up to $t$ days after the accident. That is, $S L_{t}=\left(\sum_{i=1}^{N} S L_{i,[0 ;+t]}\right) / N$, where $S L_{i,[0 ;+t]}=C A R_{i,[0 ;+t]} \times M V_{i,-1}$ and $M V_{i,-1}$ represents the market value of firm $i$ on the day before the accident (in billion dollars).

\subsection{Short-term evidence}

Figure 1 and Table 5 (Panel A) report cumulative average abnormal returns $\left(C A A R_{t}\right)$ aggregated across all accidents $(N=64) .{ }^{14}$ On average, shareholders suffer a significant loss of $0.76 \%$ on the day of the accident, and of $1.26 \%$ the following day. All these estimates are statistically significant at the $1 \%$ level. $^{15}$

It could be argued that the $C A A R_{t}$ metric is difficult to interpret since bigger firms should incur a lower drop in percentage terms. Therefore, in unreported results, in addition to the equally-weighted $C A A R_{t}$, we also computed the value-weighted $C A A R_{t}$ (see, [11]). In the shortterm, the $C A A R_{t}$ remain significantly negative, and do not change substantially the magnitude of the loss (the drop is less than $1.5 \%$ in the first two days).

About three-quarter of the firms experienced negative abnormal returns in the day following the accident, but only ten accidents caused abnormal returns significant at the $5 \%$ level. Thus, in Panel $\mathrm{B}$, we consider only the accidents which cause statistically significant negative $C A R_{i, t<10}$ at the $5 \%$ level $(N=10)$. On average, on the day of the accident, shareholders suffer an equity loss of of $2.08 \%$, which is significant at the $1 \%$ level. The cumulative returns for the following day are equal to $-3.46 \%$ (t-stat is equal to -5.10). It should be noticed that on average investor's reactions to the accidents considered by Panel B tend to persist for a longer period: the cumulative returns after twenty days are $-5.26 \%$ (t-stat is equal to -2.39). In Panel C, $C A R_{i, t}$ are aggregated across accidents which do not cause, on an accident-by-accident basis, statistically significant negative $C A R_{i, t<10}$ at the $5 \%$ level $(N=54)$. We still find that for the remaining 54 
firms cumulative average abnormal returns are negative and significant at the $5 \%$ level on the day of the accident and in the following day (-0.51\% and $-0.84 \%$, respectively). Although stock returns are volatile and, consequently, significance is difficult to detect, we provide evidence of an adverse and genuine effect of the accidents.

Over two days, the average decline in market value is equal to $\$ 306$ million. Given that accidents differ in their seriousness, so does the shareholder loss. Accordingly, the standard deviation is equal to $\$ 1.8$ billion, while the average loss is above $\$ 1$ billion for $10 \%$ of the accidents. Cross-sectional and long-term evidence in the subsequent sections is intended to investigate whether the magnitude of the losses is related to the seriousness of the accidents, which we measure by the number of casualties and the occurrence of toxic release.

\subsection{Long-term evidence}

In the empirical finance literature, evidence that stock prices continue to drift following corporate news announcements is usually attributed to two main effects: a delayed reaction and/or a premium for some unidentified risk (Bernard and Thomas, 1989). In particular, in the very short-term, investors might be slow to recognize the extent of the loss due to legal uncertainty or to lack of information about the extent of the damage. ${ }^{16}$ Moreover, if the risk profile of a firm is affected by an accident, abnormal returns might shift downward permanently. ${ }^{17}$

Our results indicate that within six months, $C A A R_{t}$ remain negative and increase slightly in magnitude, although they are not significantly different from zero, which might be due to high volatility in the long-term (see Table 5). In order to deal with the low power of event-studies as well as problems of model specification in the long-term, we look at the differences in the cumulative abnormal returns across sub-samples of accidents, as suggested by [28].

Table 6 reports cumulative average abnormal returns in the first six months after the acci-

dent for various sub-samples of accidents. Interestingly, we find that the long-term pattern of 
cumulative abnormal returns differs substantially according to the seriousness of the accident. Differences in long-term cumulative average abnormal returns across sub-samples show clear evidence that the most serious accidents are associated with abnormal return losses of higher magnitude (see Table 6). In particular, the $C A A R_{t}$ within six months of accidents with fatalities and serious injuries are about $3 \%$ higher than the ones that did not cause human harm (the difference is significant at the $1 \%$ level). Moreover, the $C A A R_{t}$ of polluting accidents are about $7 \%$ higher than that of non-polluting accidents (the difference is significant at the $1 \%$ level). Interestingly, these differences increase over time, therefore suggesting that in the short-term, the response of investors to a serious accident might not be complete. Since univariate comparisons do not account for additional factors that might simultaneously affect the response of investors, in section 4.2, we investigate whether this result is corroborated by multivariate and cross-sectional regression analysis.

\subsection{Discussion}

How do our results compare with previous evidence? A few studies provide estimates of the average market value loss associated with pollution accidents. Overall, the magnitude of their estimates, both in percentage and dollar value terms, does not substantially differ from ours. ${ }^{18}$

[26] consider a sample of 18 accidents (namely, gas leaks, explosions, chemical and oil spills) caused in 1989 and 1990 by companies listed on the NYSE and AMEX. The abnormal drop in stock returns amounts to $-1.50 \%$ over three days around the announcement, while the average dollar value loss is $\$ 360$ million (the median is $\$ 95$ million). [34] builds a sample of 14 pollution events taken from The Wall Street Journal Index from 1989 to 1993. Three categories are considered: air pollution, water pollution, and environmental pollution \& cleanup. The average abnormal return is equal to $-5.3 \%$ on the announcement day and $-2.78 \%$ in the first month (significant at the $5 \%$ level). ${ }^{19}$ [20] study pollution news about electric power and oil 
firms reported in The Wall Street Journal between 1970 and 1992. Their sample includes 14 pollution incidents (namely, radioactive release, spills, including the Exxon-Valdez oil spill and the Three Mile Island accident) as well as 84 lawsuits or settlements for environmental violations. On average, in the first two days, the loss associated with the 14 pollution accidents is equal to $-1.27 \%$, while the average dollar value loss is about $\$ 180$ million. ${ }^{20}$ However, their estimates are not significantly different from zero. It is worth noting that these studies investigate accidents that occurred in the U.S. and mainly focused on the 70s and 80s. Moreover, they use relatively small samples of accidents and only look at the very short-term.

A number of single case studies have examined catastrophic events that raised major environmental concerns. ${ }^{21}$ [35] finds that the equity value of Union Carbide decreased by $27 \%$ in the first month (from $\$ 3.5$ to $\$ 2.5$ billion) after the Bhopal explosion in 1984. [18] find that Exxon experienced a significant negative cumulative abnormal return of $-8.89 \%$ over three weeks following the Valdez oil spill, and White (1996) reports that within 120 days, the abnormal shareholder loss was significantly different from zero and equal to $20 \%{ }^{22}$ Needless to say, those accidents are rare exceptions, and no statistical inference can be drawn from a single case study. It is worth noting that our estimates in percentage value appear small by comparison with the ones found in the literature on the Bhopal explosion and the Exxon-Valdez oil spill. For the 10\% worst accidents in terms of deaths in our sample, the median abnormal loss is equal to $-1.6 \%$ over three days and $-3.3 \%$ over six months. For instance, the two most dramatic accidents in our sample are: i) the explosion of a BP refinery on March 23, 2005 in Texas, that killed 15 workers and injured more than 170 people; and ii) the explosion of the AZF-Total agrochemical plant on September 21, 2001 in France, that killed 30 people, injured 2,500 more and affected over 10,000 homes. Those accidents are associated with a market value loss equal to $\$ 3$ billion in the first days, which represents about $3 \%$ of the companies' market value. Finally, for the accidents that caused a toxic release, the median abnormal loss amounts to $-1 \%$ over three days 
and $-6.4 \%$ over six months.

Several factors could explain why shareholders' reaction appears to be smaller in percentage value in our sample. First, accidents might have less dramatic consequences due to stricter safety and environmental regulation and larger insurance coverage. ${ }^{23}$ Second, accidents might be less of a surprise for investors because transparency about the riskiness of the firms has increased. Finally, the smaller loss in percentage value can be explained by an increase in the firms' market value. In the following section, we provide cross-sectional evidence to further investigate the determinants of the shareholder loss both in terms of percentage and dollar value.

\section{How to explain the stock market response to chemical disas- ters?}

In this section, multivariate regressions are used to relate cross-sectional differences in the loss incurred by shareholders (as measured by abnormal returns and the associated market value loss) to the accident's features. Table 7 and Table 8 report the results from OLS regressions (using White-corrected standard errors) for the following two dependent variables: the cumulative abnormal returns and the shareholder loss up to $t$ days after the disaster $\left(C A R_{i,[0 ;+t]}\right.$ and $S L_{i,[0 ;+t]}$ for $\left.i=1, \ldots, 64\right)$.

The first explanatory variable is the total number of fatalities and serious injuries. The second variable of interest is a dummy set equal to 1 if accidents released toxic chemicals. A number of variables of control are included: the number of previous chemical disasters experienced by the firm since 1980; the log of the market value on the day before the accident; the abnormal media coverage received by each firm shortly before the accident; a dummy set equal to one if the accident was reported in either The Wall Street Journal or The Financial Times; a dummy set equal to one if the firm belongs to the chemical sector, and zero if it belongs to the oil industry; 
several dummy variables for accident years between 1995 and 1999, and for accidents after 2000; and four country dummy variables for accidents that happened in the United Kingdom, in continental Europe, in Japan and in emerging countries. First, we considered all variables, and then we dropped one by one the non-significant variables, with the exception of the country dummies. Model specifications are able to explain between $25 \%$ and $30 \%$ of the shareholder loss variance in the first days following the accident, as measured by the adjusted R-squared metric.

\subsection{Short-term evidence}

We first attempt to explain the magnitude of the shareholder loss in the first days after the accident (see columns (1)-(4) of Table 7 and Table 8). In what follows, we mainly comment the specifications in columns (4) of Table 7 and Table 8.

Our first result is that the human cost of an accident, as measured by the total number of fatalities and serious injuries, increases equity value losses. Since the shareholder loss dependant variable is measured in billions, one more fatality or serious injury results in an additional market value loss of $\$ 164$ million (and of $0.21 \%$ in terms of cumulative abnormal returns) over three days after the accident date, significant at the $5 \%$ level. ${ }^{24}$ More specifically, there is a $95 \%$ chance that the true population parameter lies in the interval of $[-\$ 242 ;-\$ 86]$ million per casualty. To our knowledge, no previous study has estimated the implications of workplace fatalities in hazardous industries in a multivariate regression framework. There are however various studies on airplane crashes. For instance, [5] examine a sample of 67 U.S. commercial airplane crashes from 1960 to 1985 . Using cross-section regression analysis, they find that the equity value loss per fatality (or serious injury) is of $\$ 38,000$ in 1985 dollar terms. ${ }^{25}$

Our second result is that firms that release a toxic chemical (often provoking the evacuation of thousands of persons) do incur losses of greater magnitude. All else being equal, the difference in shareholder losses between accidents with and without toxic release is equal to $\$ 1$ billion (and 
to $1.7 \%$ in terms of cumulative abnormal returns) over three days after the accident, significant at the $5 \%$ level. This population parameter has also a large standard-error, so that there is a 95\% chance that the population value stemming from any random draw of chemical accidents lies in the interval $[-\$ 1.82 ;-\$ 0.19]$ billion. This is not surprising given that the dummy cannot capture the severity of the toxic release. Notice that [24] find that in the United States, the average fine and damage award for environmental violations over the period 1980-2000 is equal to $\$ 13.2$ million, while the compliance or remediation cost is equal to $\$ 93.2$ million. But further evidence would be needed to test the hypothesis that the expected legal penalty drives the equity value loss associated with a toxic release.

Our third result is that the number of previous accidents experienced by each firm appears to aggravate the drop in equity returns in the event of chemical explosions. This result suggests that when the number of accidents previously experienced is low, investors do not update substantially their valuation of the riskiness of the firm, while when this number is high, the firm reputation is strongly damaged. One possible explanation is that investors are more likely to attribute the accident to bad luck when the responsible firm has a good environmental record. All other things being equal, this might imply a smaller stock market loss. Our result is in line with that of [33]. Using a sample of 704 judicial actions from 1977 to 1986 (385 violations on the filing date and 319 cases on the settlement date) on firms publicly listed on the NYSE, the AMEX, and the NASDAQ, they find that the stock market penalty is more pronounced for "repeat violators".

Finally, results in models (1)-(4) of Table 7, where the shareholder loss is given in percentage terms, suggest that stock market losses are stronger in Japan and continental Europe compared to the U.S. Accident-related abnormal market losses are 1.25\% higher in continental Europe than in the U.S., and $1.8 \%$ higher in Japan than in the U.S. (significant at the $10 \%$ level).

Controlling for size of firms is important. In particular, one would expect that bigger firms are less likely to be affected by accidents in percentage terms. This hypothesis is supported by 
the data, since coefficients are significant at the $5 \%$ level in models where the dependant variable is given in percentage terms. We also find that abnormal losses are lower for firms which are of major concern for journalists in the period before the disaster. It appears that the abnormal media coverage variable has a positive effect on abnormal returns, which is significant at the $5 \%$ level. Notice that the firm's size and the firm abnormal media coverage before the accident do not affect the absolute value of the loss as shown in models (1) to (4) of Table 8.

Finally, other variables do not appear significant. In particular, this the case for the time dummies, which are suited to control for increased public concern about safety and pollution news, as illustrated by the rise of voluntary initiatives as well as greater transparency at the end of the 1990s. It could be the case that these effects are captured by country dummies and the reputation variable.

\subsection{Long-term evidence}

In columns (5)-(6) of Table 7, the dependant variable is the shareholder loss (in percentage terms) over six months after the accident, as measured by the cumulative abnormal returns up to 120 trading days. Using robust ordinary least squares, we document that, after six months, the additional loss associated with pollution occurrence is $12 \%$. This finding, which is both statistically and economically significant at the $5 \%$ level, might reflect a premium for some unidentified risk raised by the occurrence of pollution. By contrast, we find that the effect of the number of serious injuries and fatalities on abnormal returns in the long-term is not significantly different from zero.

We also find that firms associated with bad environmental records are more strongly penalized on stock markets, even six months after the accident, as the number of previous accidents experienced by each firm significantly aggravates the shareholder loss. Finally, as in the short-

term, we observe that firms which experience an accident in the U.S incur abnormal losses of 
lower magnitude than firms that experience an accident in the other countries. One possible explanation is that in the U.S., possibly due to stricter regulation and better transparency, investors are more confident about the riskiness of the firm and, consequently, react less after a disaster. These results confirm previous studies arguing that the strength of governmental regulation is an important predictor of the stock market response to a broad set of pollution news. In particular, [8], [9], and [14] show that stock market losses following the publication of pollution records by governmental authorities or by the press in developing countries are more pronounced than in the U.S. and Canada. 


\section{Conclusion}

This paper examines the financial cost incurred by firms responsible for industrial disasters. To do this, we built an original dataset of 64 explosions in the petrochemical industry over the period 1990-2005. A quarter of the accidents in our sample resulted in a toxic release, and half of them caused at least one death or serious injury.

Our results show that the stock market reacts negatively (and instantaneously) after the accident. On average, we find that shareholders suffer a significant loss of about $-1.3 \%$ over the two days following a disaster. Multivariate analysis finds that losses in the first days are strongly related to the seriousness of the accident. One fatality or serious injury is associated with an additional loss of $\$ 164$ million, while the occurrence of a toxic release corresponds to an additional drop of around $\$ 1$ billion. We also observe that stock market losses are more severe for firms that have bad environmental and safety records. This result suggests that investors are less likely to change their belief about the riskiness of a firm when the number of accidents previously experienced is low.

We also study the stock abnormal returns over longer event windows and find that accidents that caused a toxic release are associated with higher losses than non-polluting accidents. Moreover, we show that this difference increases over time. The latter result suggests that investors might be slow to recognize the extent of the loss after a polluting accident, possibly due to greater legal uncertainty or to lack of information with regard to the seriousness of the accident in the very short-term.

Since we have shown that losses are proportional to the social cost of the accident, our results provide some support to the idea that stock markets improve incentives for risk mitigation. However, it remains questionable whether the magnitude of the expected drop, as evidenced in our study, represents a serious threat for managers and provides sufficient incentives to improve 
environmental and occupational safety. This important topic is beyond the scope of this paper and is left for future research. 


\section{References}

[1] S. G. Badrinath and P.J. Bolster, The Role of Market Forces in EPA Enforcement Activity, Journal of Regulatory Economics 10(2), 165-181 (1996).

[2] W.B. Barrett, A.J. Heuson and R.W. Kolb, The Effect of Three Mile Island on Utility Bond Risk Premia: A Note, The Journal of Finance, 41(1), 255-261 (1986).

[3] V.L. Bernard and J.K. Thomas, Delayed Price Response or Risk Premium?, Journal of Accounting Research 27, 1-36 (1989).

[4] W.G. Blacconiere and D.M. Patten, Environmental Disclosures, Regulatory Costs, and Changes in Firm Value, Journal of Accounting and Economics 18, 357-377 (1994).

[5] S. Borenstein and M.B. Zimmerman, Market incentives for safe commercial airline operation, The American Economic Review 78(5), 913-935 (1988).

[6] R.M. Bowen, R.P. Castanias and L.A. Daley, Intra-industry effects of the accident at Three Mile Island, The Journal of Financial and Quantitative Analysis 18(1), 87-111 (1983).

[7] M.A. Cohen and V. Santhakumar, Information Disclosure as Environmental Regulation: A Theoretical Analysis, Environmental \& Resource Economics 37, 599-620 (2007).

[8] S. Dasgupta, B. Laplante and N. Mamingi, Pollution and Capital Markets in Developing Countries, Journal of Environmental Economics and Management 42(3), 310-335 (2001).

[9] S. Dasgupta, H.J. Hong, B. Laplante and N. Mamingi, Disclosure of environmental violations and the stock market in the Republic of Korea, Ecological Economics 58(4), 759-777 (2006).

[10] M.R. Elliott, Y. Wang, R.A. Lowe and P.R. Kleindorfer, Environmental justice: frequency and severity of US chemical industry accidents and the socioeconomic status of surrounding communities, Journal of Epidemiology and Community Health 58, 24-30 (2004).

[11] E.F. Fama, Market Efficiency, Long-term Returns, and Behavioral Finance, Journal of Financial Economics 49(3), 283-306 (1998). 
[12] A. Fields and V. Janjigian, The effect of Chernobyl on electric-utility stock prices, Journal of Business Research 18, 81-88 (1989).

[13] P.K. Freeman and H. Kunreuther, Managing risk through insurance, Yearbook of Environmental and Resource Economics (2007).

[14] S. Gupta and B. Goldar, Do stock markets penalize environment -unfriendly behaviour? Evidence from India, Ecological Economics 52, 81-95 (2005).

[15] J.T. Hamilton, Pollution as News: Media and Stock Market Reactions to the Toxic Release Inventory Data, Journal of Environmental Economics and Management 28(1), 98-103 (1995).

[16] J.K. Hammitt, J.B. Wiener, B.Swedlow, D. Kall, and Z.Zhou, Precautionary Regulation in Europe and the United States: A Quantitative Comparison, Risk Analysis 25(5), 1215-1228 (2005).

[17] R.K. Harper and S.C. Adams, CERCLA and Deep Pockets: Market Response to the Superfund Program, Contemporary Economic Policy 14, 107-115 (1996).

[18] A.F. Herbst, J.F. Marshall and J. Wingender, An Analysis of the Stock Market's Response to the Exxon Valdez Disaster, Global Finance Journal 7(1), 101-114 (1996).

[19] J. Hill and T. Schneeweis, The effect of Three Mile Island on electric utility stock prices: a note, Journal of Finance 38, 1285-1292 (1983).

[20] K. Jones and P.H. Rubin, Effects of harmful environmental events on reputations of firms, Advances in Financial Economics (M. Hirschey, K. John, and A. Makhija eds.) 6, 161-182 (2001).

[21] J.D. Jones, Ch.L. Jones and F. Phillips-Patrick, Estimating the Costs of the Exxon-Valdez Oil Spill, Research in Law and Economics 16, 109-149 (1994).

[22] R. Kalra, G.V. Henderson and G.A. Raines, Effects of the Chernobyl nuclear accident on utility share prices, Quarterly Joumal of Business and Economics 32, 52-78 (1993).

[23] R. Kalra, G.V. Henderson and G.A. Raines, Contagion Effects in the Chemical Industry following the Bhopal disaster, Journal Of Financial and Strategic Decisions 8(2), 1-11 (1995). 
[24] J.M. Karpoff, J.R.Jr. Lott andE. W.Wehrly, The Reputational Penalties for Environmental Violations: Empirical Evidence, Journal of Law and Economics 48, October (2005).

[25] M. Khanna, W.R.H. Quimio and D. Bojilova, Toxic Release Information: A Policy Tool for Environmental Protection, Journal of Environmental Economics and Management 36(3), 243-266 (1998).

[26] R.D. Klassen and C.P. McLaughlin, The impact of Environmental Management on Firm Performance, Management Science 42(8), 1199-1214 (1996).

[27] S. Konar and M.A. Cohen, Information as regulation: The effect of community right to know laws on toxic emissions, Journal of Environmental Economics and Management 32(1), 109-124 (1997).

[28] S. Kothari and J. Warner, Econometrics of Event Studies, in Espen Eckbo, Ed., Handbook of Empirical Corporate Finance, Elsevier-North-Holland (2006).

[29] P. Lanoie and B. Laplante, The market response to environmental incidents in Canada: a theoretical and empirical analysis, Southern Economic Journal 60, 657-72 (1994).

[30] R. La Porta, F. Lopez-de-Silanes and A. Schleifer, and R. Vishny, Investor Protection and Corporate Valuation, The Journal of Finance 42(3), 1147-1170 (2002).

[31] A.C. MacKinlay, Event Studies in Economics and Finance, Journal of Economic Literature 35(1), 13-39 (1997).

[32] I. Mansur, S. J. Cochran and J. E. Phillips, The Relationship between the Equity Return Levels of Oil Companies and Unanticipated Events: The Case of the Exxon Valdez Incident, Logistics and Transportation Review 38, 241-255 (1991).

[33] M. Muoghalu, H.D. Robison and J.L. Glascock, Hazardous Waste Lawsuits, Stockholder Returns, and Deterrence, Southern Economic Journal 7(2), 357-70 (1990).

[34] S.M. Rao, The Effect of Published Reports of Environmental Pollution on Stock Prices, Journal of Financial and Strategic Decisions 9(1), 25-32 (1996).

[35] M. Salinger, Value Event Studies, Review of Economics and Statistics 74(4), 671-77 (1992). 
[36] R.E. Spudeck and C. Moyer, A note on the stock market's reaction to the accident at Three Mile Island, Journal of Economics and Business 41, 235-241 (1989).

[37] T. Tietenberg, Disclosure strategies for pollution control, Environmental and Resource Economics, 11(3-4), 587-602 (1998).

[38] V.P. Viscusi, The value of life in legal contexts: survey and critique, American Law and Economics Review, 2(1), 195-210 (2000).

[39] M. Yamashita, S. Sen, and M.C. Roberts, The Rewards for Environmental Conscientiousness in the US Capital Markets, Journal of Financial and Strategic Decisions 12, 73-82 (1999).

[40] X.F. Zhang, Information Uncertainty and Stock Returns, Journal of Finance 61(1), 105-137 (2006). 
A Appendix 


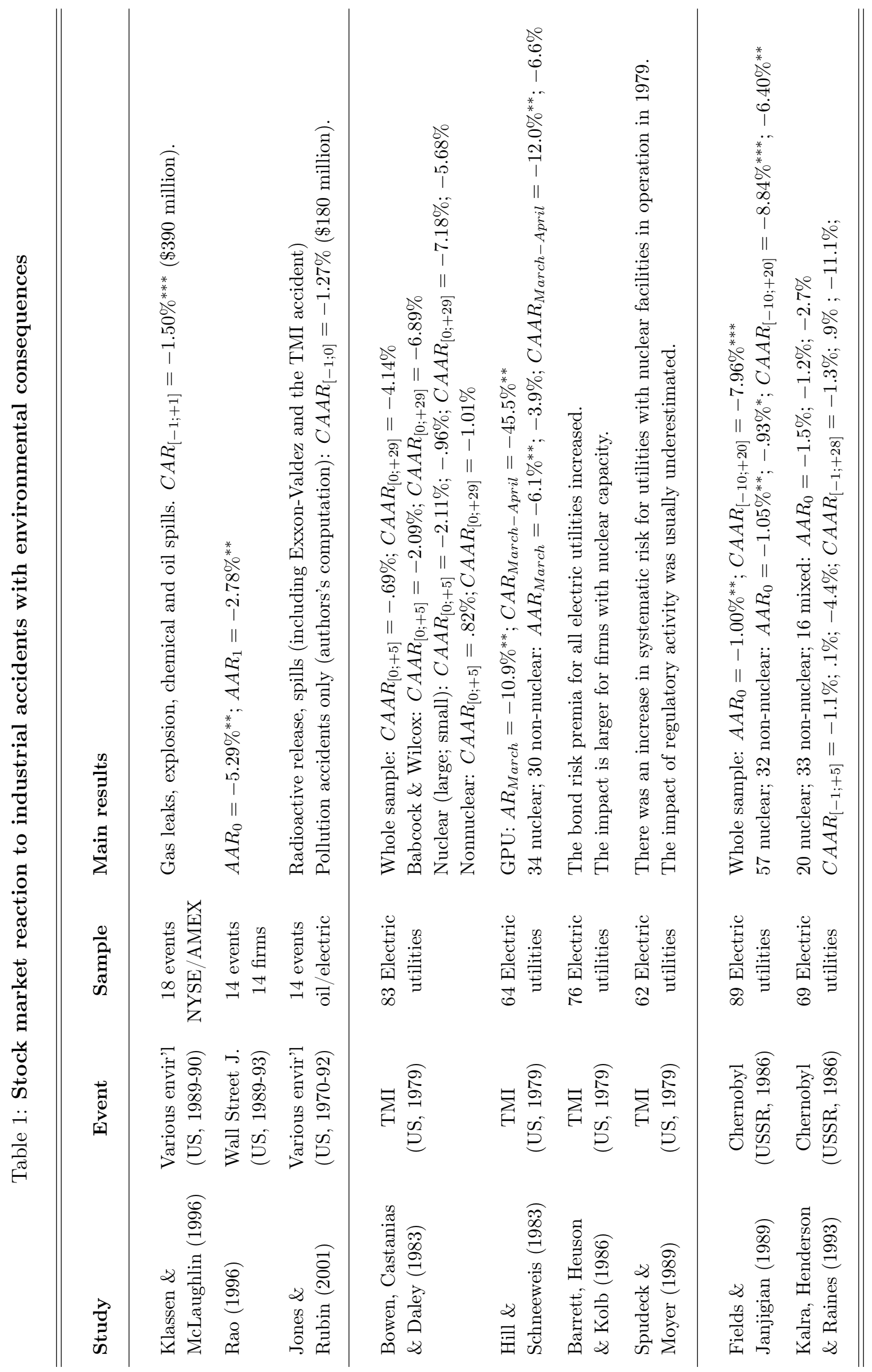




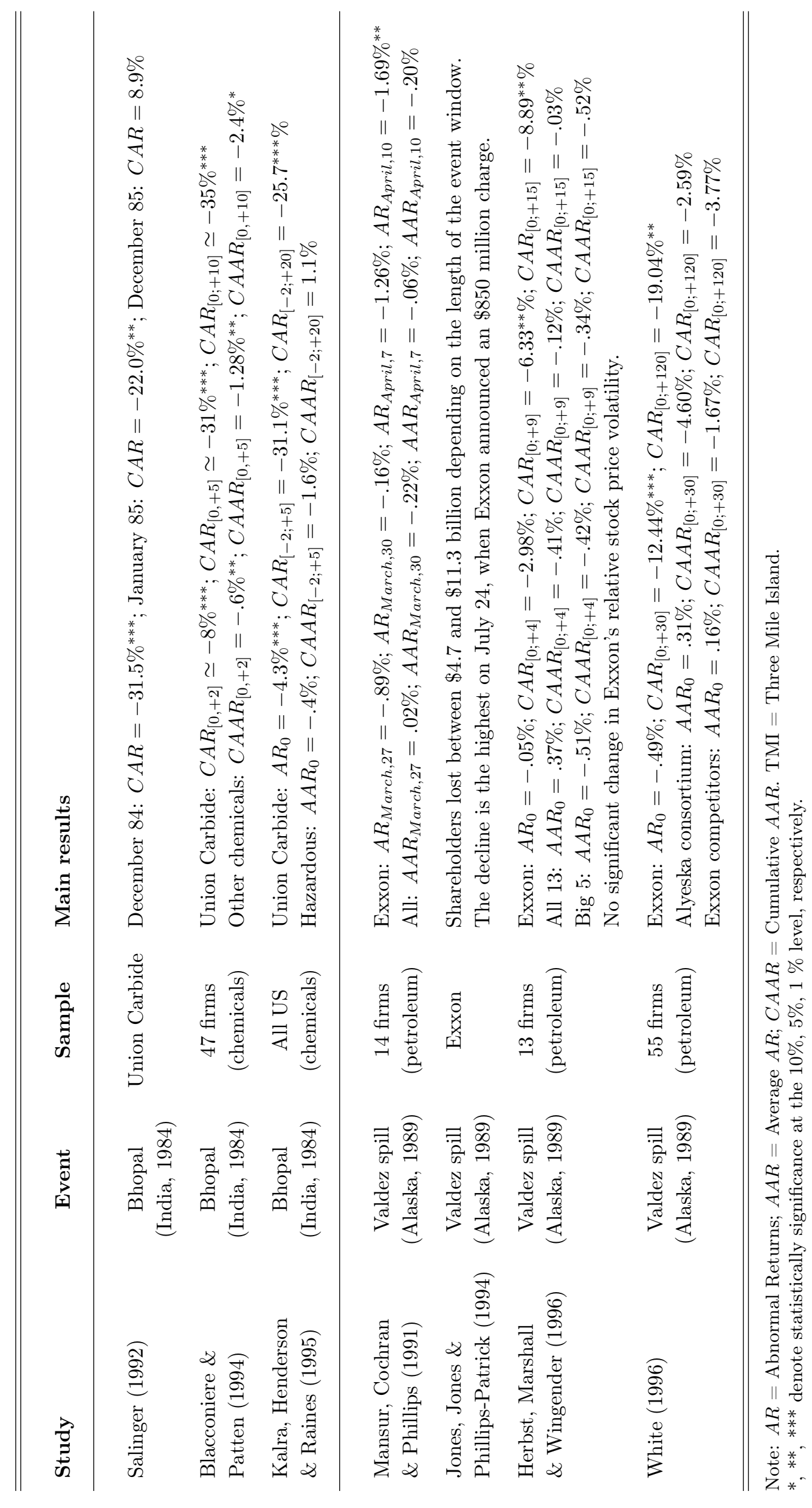


Table 2: List of accidents and main features

\begin{tabular}{|c|c|c|c|c|c|c|c|}
\hline Date & Firm & $\begin{array}{l}\text { Listing } \\
\text { Country }\end{array}$ & $\begin{array}{l}\text { Accident } \\
\text { Country }\end{array}$ & $\begin{array}{c}\text { \# Serious } \\
\text { injuries and } \\
\text { fatalities }\end{array}$ & $\begin{array}{c}\text { Dummy }= \\
1 \text { if Toxic } \\
\text { release }\end{array}$ & $\begin{array}{l}\text { \# print } \\
\text { media } \\
\text { articles }\end{array}$ & $\begin{array}{l}\text { Sales } \\
\text { in USD } \\
\text { million }\end{array}$ \\
\hline $03 / 20 / 90$ & Royal Dutch Ptl. & NL & UK & 0 & 1 & 12 & 66.79 \\
\hline $05 / 26 / 90$ & Daiichi Pharm. & JAP & JAP & 7 & 0 & 5 & 1.49 \\
\hline $07 / 19 / 90$ & BASF & GER & USA & 5 & 0 & 23 & 32.81 \\
\hline 03/12/91 & Union Carbide & USA & USA & 1 & 0 & 25 & 7.62 \\
\hline 06/17/91 & Tenneco & USA & USA & 12 & 0 & 21 & NA \\
\hline $12 / 13 / 91$ & DSM & NL & NL & 7 & 0 & 9 & 6.16 \\
\hline $02 / 10 / 92$ & $\mathrm{BP}$ & UK & UK & 3 & 0 & 15 & 49.31 \\
\hline $04 / 22 / 92$ & Elf Aquitaine & FRA & FRA & 1 & 0 & 1 & 37.05 \\
\hline $04 / 22 / 92$ & Air Liquide & FRA & FRA & 1 & 0 & 1 & 5.87 \\
\hline 09/08/92 & Akzo Nobel & NL & NL & 1 & 0 & 2 & 9.26 \\
\hline $11 / 09 / 92$ & Total & FRA & FRA & 6 & 0 & 22 & 26.41 \\
\hline $01 / 26 / 93$ & Lubrizol & USA & USA & 0 & 1 & 1 & 1.54 \\
\hline $02 / 22 / 93$ & Hoechst & GER & GER & 0 & 1 & 4 & 26.26 \\
\hline $03 / 15 / 93$ & Hoechst & GER & GER & 2 & 1 & 24 & 26.26 \\
\hline $05 / 02 / 93$ & Dow Chemicals & USA & GER & 1 & 0 & 1 & 18.97 \\
\hline $05 / 03 / 93$ & Marathon Oil & USA & USA & 0 & 0 & 1 & 12.78 \\
\hline $07 / 04 / 93$ & Sumitomo Chemical & JAP & JAP & 1 & 0 & 28 & 9.11 \\
\hline 08/02/93 & Exxon Mobil & USA & USA & 3 & 1 & 18 & 100.03 \\
\hline $04 / 08 / 94$ & Olin & USA & USA & 0 & 0 & 3 & 2.42 \\
\hline $05 / 27 / 94$ & Royal Dutc Ptl. & NL & USA & 3 & 0 & 62 & 58.99 \\
\hline 06/04/94 & $\mathrm{BP}$ & UK & FRA & 4 & 0 & 4 & 54.66 \\
\hline $08 / 08 / 94$ & Exxon Mobil & USA & USA & 0 & 0 & 32 & 97.82 \\
\hline $10 / 15 / 94$ & Rohm Haas & USA & USA & 0 & 1 & 3 & 3.27 \\
\hline $04 / 04 / 95$ & Crompton & USA & CAN & 1 & 0 & 5 & 0.59 \\
\hline $08 / 16 / 95$ & Ashland & USA & USA & 0 & 0 & 1 & 9.46 \\
\hline $08 / 20 / 95$ & Du Pont De Nemours & USA & USA & 0 & 1 & 8 & 34.04 \\
\hline $11 / 21 / 95$ & Lyondell Chemical & USA & USA & 0 & 0 & 2 & 3.86 \\
\hline $12 / 05 / 95$ & Ak Steel Hdg. & USA & USA & 1 & 0 & 19 & NA \\
\hline $12 / 05 / 95$ & FMC & USA & USA & 0 & 1 & 19 & 4.01 \\
\hline $12 / 29 / 95$ & Mitsubishi Chem. & JAP & JAP & 1 & 0 & 2 & 10.45 \\
\hline $01 / 27 / 96$ & Hoechst & GER & GER & 1 & 1 & 13 & 33.33 \\
\hline $04 / 01 / 96$ & Crompton & USA & USA & 1 & 0 & 3 & 0.66 \\
\hline $07 / 17 / 96$ & Mitsui Chemicals & JAP & JAP & 1 & 0 & 9 & 3.11 \\
\hline $10 / 03 / 96$ & Albright \& Wilson & UK & UK & 0 & 1 & 26 & 1.19 \\
\hline $11 / 17 / 96$ & FMC & USA & USA & 0 & 0 & 6 & 4.51 \\
\hline $12 / 04 / 96$ & FMC & USA & USA & 0 & 0 & 2 & 4.51 \\
\hline $12 / 22 / 96$ & Wyman Gordon & USA & USA & 8 & 0 & 68 & 0.40 \\
\hline $04 / 04 / 97$ & Du Pont De Nemours & USA & JAP & 0 & 0 & 2 & 38.35 \\
\hline $04 / 04 / 97$ & Mitsui Chemicals & JAP & JAP & 0 & 0 & 2 & 3.01 \\
\hline $12 / 23 / 98$ & Sumitomo Chemical & JAP & JAP & 0 & 0 & 2 & 8.98 \\
\hline 06/08/99 & Bayer & GER & GER & 0 & 1 & 14 & 28.28 \\
\hline $03 / 23 / 00$ & Royal Dutch Ptl. & NL & GER & 0 & 0 & 1 & 55.53 \\
\hline 06/07/00 & $\mathrm{BP}$ & UK & UK & 0 & 0 & 30 & 77.21 \\
\hline $06 / 10 / 00$ & $\mathrm{BP}$ & UK & UK & 0 & 1 & 41 & 77.21 \\
\hline
\end{tabular}




\begin{tabular}{llllcccc}
$09 / 03 / 00$ & Total & FRA & FRA & 0 & 0 & 3 & 39.21 \\
$10 / 12 / 00$ & Solutia & USA & GER & 0 & 0 & 4 & 2.83 \\
$12 / 09 / 00$ & Exxon Mobil & USA & SG & 3 & 0 & 8 & 160.90 \\
$04 / 25 / 01$ & Rhodia & FRA & FRA & 1 & 0 & 1 & 6.61 \\
$07 / 14 / 01$ & Total & FRA & USA & 3 & 1 & 79 & 102.10 \\
$09 / 21 / 01$ & Total & FRA & FRA & 30 & 0 & 267 & 102.10 \\
$03 / 12 / 02$ & Asahi Kasei & JAP & JAP & 0 & 1 & 42 & 10.70 \\
$09 / 03 / 02$ & Guerbet & FRA & FRA & 0 & 0 & 0 & 0.22 \\
$01 / 08 / 03$ & Rhodia & FRA & FRA & 0 & 1 & 2 & 8.35 \\
$01 / 12 / 03$ & Marathon Oil & USA & USA & 0 & 0 & 14 & 31.46 \\
$02 / 21 / 03$ & Exxon Mobil & USA & USA & 3 & 0 & 108 & 178.90 \\
$08 / 13 / 03$ & DSM & NL & AUS & 2 & 0 & 9 & 7.11 \\
$08 / 14 / 03$ & Repsol YPF & SP & SP & 10 & 0 & 46 & 44.85 \\
$02 / 22 / 04$ & Lonza Group & SW & SW & 0 & 0 & 9 & 1.98 \\
$03 / 31 / 04$ & BP & UK & USA & 0 & 0 & 74 & 272.80 \\
$06 / 11 / 04$ & Crompton & USA & CAN & 0 & 0 & 15 & 2.18 \\
$08 / 25 / 04$ & LG Petrochemical & SK & SK & 2 & 0 & 8 & 1.21 \\
$09 / 01 / 04$ & Sasol & SA & SA & 10 & 0 & 64 & 11.48 \\
$01 / 04 / 05$ & Yara & NOR & FRA & 0 & 0 & 0 & 6.37 \\
$03 / 23 / 05$ & BP & UK & USA & 15 & 0 & 836 & 266.70 \\
\hline \hline
\end{tabular}


Table 3: Descriptive statistics for the sample of accidents in the petro-chemical industry

The sample is composed of 64 accidents in the petrochemical industry over the period 1990-2005. Accidents are identified using the software Factiva. Only publicly listed firms are considered.

\begin{tabular}{|c|c|c|c|c|c|c|}
\hline & Mean & Median & Std. Dev. & Min & Max & $\begin{array}{c}\text { Expected } \\
\text { effect on } \\
\text { stock value }\end{array}$ \\
\hline \multicolumn{7}{|l|}{ Variables of interest } \\
\hline Ser. injuries and fatalities & 2.36 & 1 & 4.76 & 0 & 30 & $<0$ \\
\hline Toxic release & 0.23 & 0 & 0.43 & 0 & 1 & $<0$ \\
\hline \# previous accidents & 2.69 & 1.50 & 3.42 & 0 & 16 & $?$ \\
\hline \multicolumn{7}{|l|}{ Variables of control } \\
\hline Market value (billion, 2005\$) & 43.36 & 7.28 & 74.04 & 0.10 & 340.05 & $?$ \\
\hline Abnormal Media Coverage & 0.06 & 0.05 & 0.03 & 0 & 0.2 & $?$ \\
\hline Chemicals & 0.68 & 1 & 0.47 & 0 & 1 & $?$ \\
\hline $1994<$ Accident date $<2000$ & 0.28 & 0 & 0.45 & 0 & 1 & $?$ \\
\hline Accident date $>1999$ & 0.36 & 0 & 0.48 & 0 & 1 & $?$ \\
\hline \multicolumn{7}{|l|}{ Country of listing } \\
\hline US & 0.36 & 0 & 0.48 & 0 & 1 & $?$ \\
\hline Continental Europe & 0.32 & 0 & 0.47 & 0 & 1 & $?$ \\
\hline Japan & 0.11 & 0 & 0.31 & 0 & 1 & $?$ \\
\hline Emerging countries & 0.06 & 0 & 0.24 & 0 & 1 & $?$ \\
\hline \multicolumn{7}{|l|}{ Country of accident } \\
\hline US & 0.39 & 0 & 0.49 & 0 & 1 & $?$ \\
\hline Continental Europe & 0.33 & 0 & 0.47 & 0 & 1 & $?$ \\
\hline Japan & 0.12 & 0 & 0.33 & 0 & 1 & $?$ \\
\hline Emerging countries & 0.06 & 0 & 0.24 & 0 & 1 & $?$ \\
\hline
\end{tabular}

Abbreviations: Ser. injuries and fatalities: Number of serious injuries or fatalities; Toxic release $=1$ if the accident caused a toxic release and 0 otherwise; \# previous accident: Number of previous accidents experienced by the firm (in our database) since the 1980s; Abnormal Media Coverage: ratio of headlines mentioning the firm over twenty days before disasters to the total number of headlines received in the previous year; Accident Date $>1999$ $=1$ if the accident occurred after 1999 and 0 otherwise. See the text for further details concerning the sample and the variables. 


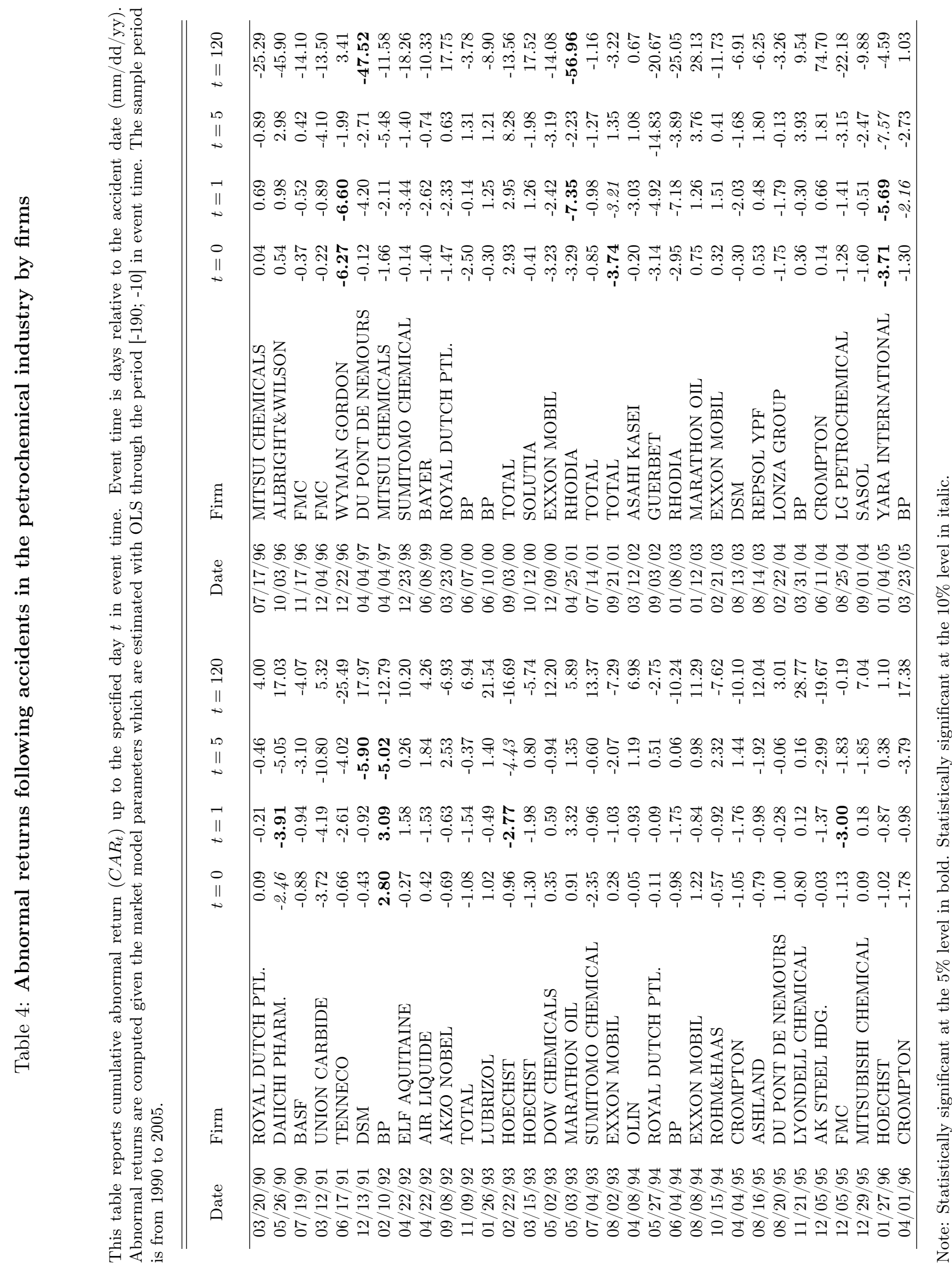


Figure 1: Abnormal Returns with Confidence Intervals at the $5 \%$ level

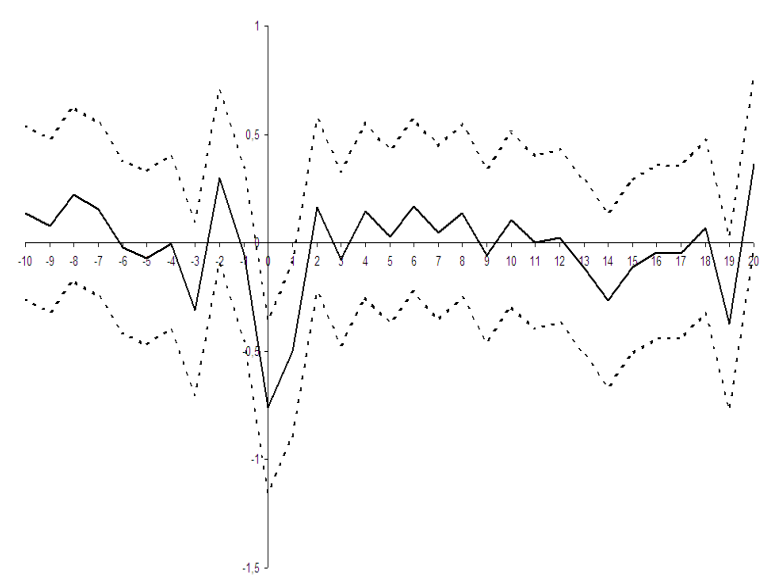

(a) Average abnormal returns (in \%)

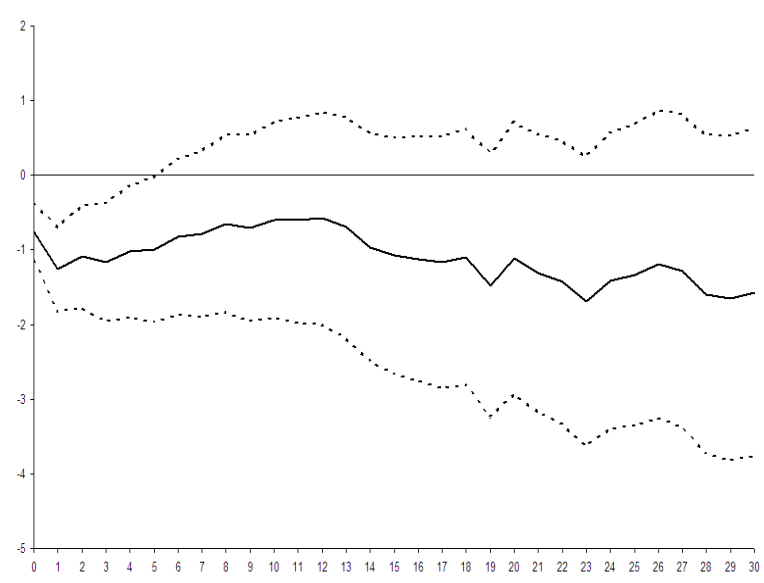

(b) Cumulative average abnormal returns (in \%)

Notes: Abnormal returns are computed given the market model parameters estimated with OLS through the period $[-190 ;-10]$ in event time. Event time is days relative to the accident date. The sample is composed of 64 accidents in the petrochemical industry over the period 1990-2005. 


\section{Table 5: Abnormal returns following accidents in the petrochemical industry}

This table reports cumulative average abnormal return $\left(C A A R_{t}\right)$ up to the specified day $t$ in event time (in $\%)$. Event time is days relative to the accident date. Abnormal returns are computed given the market model parameters which are estimated with OLS through the period $[-190 ;-10]$ in event time. $C A R_{i t}<0$ is the percentage of firms $i$ with a negative $C A R_{i t}$. Panel A: All accidents. Panel B: Accidents which cause statistically significant negative $C A R_{i t, t<10}$ at the $5 \%$ level. Panel C: Panel A less Panel B. The sample period is from 1990 to 2005 .

\begin{tabular}{|c|c|c|c|c|c|c|c|c|c|}
\hline \multicolumn{4}{|c|}{ Panel A: 64 events } & \multicolumn{3}{|c|}{ Panel B: 10 events } & \multicolumn{3}{|c|}{ Panel C: 54 events } \\
\hline$t$ & $C A A R_{t}$ & t-stat & $C A R_{i t}<0$ & $C A A R_{t}$ & $t$-stat & $C A R_{i t}<0$ & $C A A R_{t}$ & t-stat & $C A R_{i t}<0$ \\
\hline 0 & $-0.76^{* * *}$ & -3.75 & $71 \%$ & $-2.08 * * *$ & -4.35 & $90 \%$ & $-0.51^{* *}$ & -2.28 & $68 \%$ \\
\hline 1 & $-1.26^{* * *}$ & -4.40 & $76 \%$ & $-3.46^{* * *}$ & -5.10 & $90 \%$ & $-0.84 * * *$ & -2.68 & $74 \%$ \\
\hline 2 & $-1.09^{* * *}$ & -3.12 & $63 \%$ & $-4.00^{* * *}$ & -4.82 & $90 \%$ & -0.54 & -1.41 & $58 \%$ \\
\hline 3 & $-1.17 * * *$ & -2.88 & $63 \%$ & $-4.53 * * *$ & -4.72 & $100 \%$ & -0.53 & -1.20 & $57 \%$ \\
\hline 4 & $-1.02^{* *}$ & -2.26 & $63 \%$ & $-3.99 * * *$ & -3.73 & $100 \%$ & -0.46 & -0.93 & $57 \%$ \\
\hline 5 & $-0.99^{* *}$ & -2.01 & $57 \%$ & $-3.93^{* * *}$ & -3.35 & $90 \%$ & -0.44 & -0.81 & $51 \%$ \\
\hline 6 & -0.83 & -1.54 & $61 \%$ & $-4.22^{* * *}$ & -3.33 & $90 \%$ & -0.19 & -0.32 & $57 \%$ \\
\hline 7 & -0.78 & -1.37 & $57 \%$ & $-4.88^{* * *}$ & -3.60 & $90 \%$ & -0.01 & -0.02 & $51 \%$ \\
\hline 8 & -0.65 & -1.06 & $50 \%$ & $-4.97 * * *$ & -3.46 & $90 \%$ & 0.17 & 0.25 & $43 \%$ \\
\hline 9 & -0.71 & -1.10 & $53 \%$ & $-4.87^{* * *}$ & -3.22 & $80 \%$ & 0.08 & 0.11 & $49 \%$ \\
\hline 10 & -0.60 & -0.90 & $52 \%$ & $-4.64^{* * *}$ & -2.92 & $80 \%$ & 0.16 & 0.22 & $47 \%$ \\
\hline 20 & -1.11 & -1.20 & $60 \%$ & $-5.26^{* *}$ & -2.39 & $80 \%$ & -0.33 & -0.33 & $57 \%$ \\
\hline 40 & -1.80 & -1.37 & $66 \%$ & $-5.65^{*}$ & -1.75 & $80 \%$ & -1.09 & -0.76 & $64 \%$ \\
\hline 60 & -2.07 & -1.29 & $62 \%$ & -6.44 & -1.63 & $90 \%$ & -1.26 & -0.73 & $58 \%$ \\
\hline 80 & -2.13 & -1.16 & $64 \%$ & -4.28 & -0.94 & $80 \%$ & -1.71 & -0.85 & $62 \%$ \\
\hline 100 & -2.78 & -1.35 & $58 \%$ & -7.85 & -1.55 & $80 \%$ & -1.86 & -0.83 & $55 \%$ \\
\hline 120 & -2.70 & -1.20 & $58 \%$ & $-12.59^{* *}$ & -2.27 & $70 \%$ & -0.97 & -0.40 & $57 \%$ \\
\hline
\end{tabular}

Note: $* * *, * * *$ denote statistically significance at the $10 \%$, the $5 \%$ and the $1 \%$ level, respectively. 


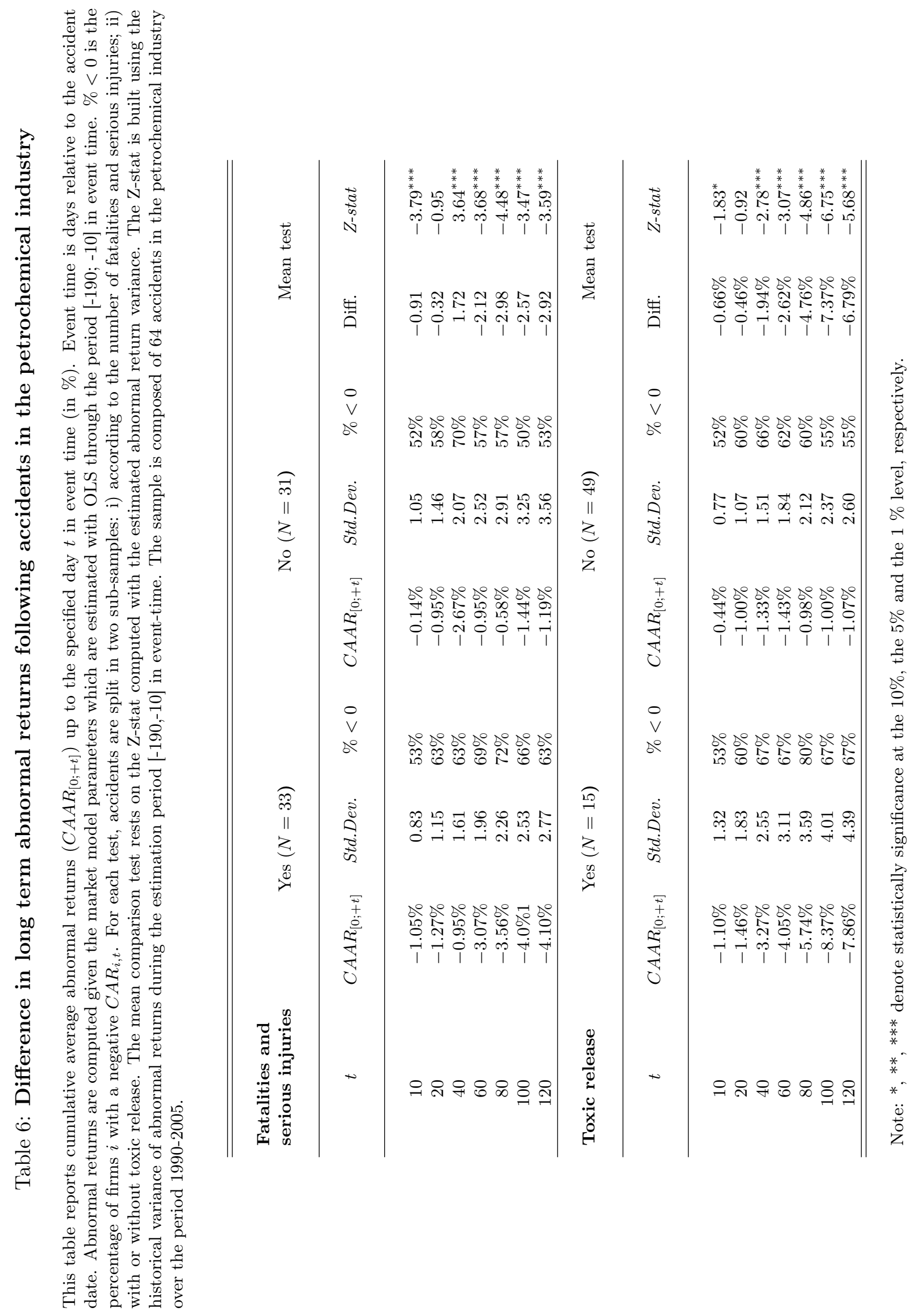




\section{Table 7: Determinants of Abnormal Returns Following Accidents in the Petro- chemical Industry}

This table reports results from least squares regressions (using White-corrected standard errors). The dependent variable is the Cumulative Abnormal Returns up to $t$ days following the disaster: $C A R_{i,[0 ;+t]}$ for $i=1, \ldots, 64$ and $t=1,2$ and $t=120$. Abnormal returns are computed using the market model. Models (5) and (6) also include a set of monthly dummies. The sample is composed of 64 accidents in the petrochemical industry over the period 1990-2005. Accidents are identified using the software Factiva.

\begin{tabular}{|c|c|c|c|c|c|c|}
\hline \multirow[b]{2}{*}{ Model } & $1 R_{[0 ;+1]}$ & \multicolumn{2}{|c|}{$C A R_{[0 ;+2]}$} & \multicolumn{3}{|c|}{$C A R_{[0 ;+2]} C A R_{[0 ;+120]} C A R_{[0 ;+120]}$} \\
\hline & (1) & $(2)$ & $(3)$ & (4) & $(5)$ & (6) \\
\hline \multirow[t]{2}{*}{ Constant } & $-1.549^{* *}$ & $-1.674^{* * *}$ & $-2.620^{* *}$ & $-2.045^{* * *}$ & 23.998 & $16.779^{*}$ \\
\hline & {$[0.731]$} & {$[0.485]$} & {$[1.219]$} & {$[0.707]$} & [17.309] & {$[8.590]$} \\
\hline \multirow[t]{2}{*}{ Fatalities and serious injuries } & $-0.128^{* *}$ & $-0.120^{* * *}$ & $-0.216^{* * *}$ & $-0.216^{* * *}$ & 0.044 & 0.258 \\
\hline & {$[0.051]$} & {$[0.042]$} & {$[0.067]$} & {$[0.057]$} & {$[0.362]$} & {$[0.313]$} \\
\hline \multirow[t]{2}{*}{ Toxic release } & $-1.846^{* * *}$ & $-1.724^{* * *}$ & $-2.047^{* *}$ & $-1.860^{* *}$ & $-10.551^{*}$ & $-12.412^{* *}$ \\
\hline & {$[0.598]$} & {$[0.575]$} & {$[0.867]$} & {$[0.824]$} & {$[5.518]$} & {$[4.683]$} \\
\hline \multirow[t]{2}{*}{ \# Previous accidents } & $-0.183^{*}$ & $-0.167^{* *}$ & -0.170 & -0.163 & $-2.252^{* *}$ & $-2.332^{* * *}$ \\
\hline & {$[0.093]$} & {$[0.071]$} & {$[0.137]$} & {$[0.121]$} & {$[0.926]$} & {$[0.854]$} \\
\hline \multirow{2}{*}{ Market value $(\$ 2005, \log )$} & $0.590^{* * *}$ & $0.591^{* * *}$ & $0.685^{* *}$ & $0.608^{* *}$ & -0.780 & 0.054 \\
\hline & {$[0.194]$} & {$[0.177]$} & {$[0.262]$} & {$[0.251]$} & {$[2.004]$} & {$[1.504]$} \\
\hline \multirow[t]{2}{*}{ Abnormal media coverage } & $0.169^{*}$ & $0.182^{* *}$ & $0.325^{* * *}$ & $0.334^{* * *}$ & -0.158 & \\
\hline & {$[0.098]$} & {$[0.085]$} & {$[0.112]$} & {$[0.099]$} & {$[0.814]$} & \\
\hline \multirow[t]{2}{*}{ Financial press dummy } & 0.638 & & 0.494 & & 8.213 & \\
\hline & {$[0.573]$} & & {$[0.752]$} & & {$[6.124]$} & \\
\hline \multirow[t]{2}{*}{ Chemical industry } & 0.101 & & 0.362 & & -1.724 & \\
\hline & {$[0.784]$} & & {$[1.153]$} & & {$[10.331]$} & \\
\hline \multirow[t]{2}{*}{$1994<$ Accident year $<2000$} & -0.338 & & 0.370 & & $-11.687^{*}$ & \\
\hline & {$[0.638]$} & & {$[0.869]$} & & {$[6.522]$} & \\
\hline \multirow[t]{2}{*}{ Accident year > 1999} & -0.593 & & -0.260 & & -4.093 & \\
\hline & {$[0.585]$} & & {$[0.791]$} & & {$[10.306]$} & \\
\hline \multirow[t]{2}{*}{ Japan } & $-2.066^{* * *}$ & $-1.875^{* *}$ & $-1.860^{*}$ & -1.517 & -11.968 & $-15.153^{* *}$ \\
\hline & {$[0.734]$} & {$[0.726]$} & {$[0.978]$} & {$[0.964]$} & {$[8.565]$} & {$[7.336]$} \\
\hline \multirow[t]{2}{*}{ Continental Europe } & $-1.125^{*}$ & $-1.138^{*}$ & -1.318 & $-1.455^{*}$ & $-16.347^{* *}$ & $-12.910^{*}$ \\
\hline & {$[0.571]$} & {$[0.588]$} & {$[0.811]$} & {$[0.796]$} & [7.199] & {$[7.082]$} \\
\hline \multirow[t]{2}{*}{ UK } & 1.187 & 1.297 & 1.236 & 1.187 & $-23.421^{* *}$ & $-18.231^{* *}$ \\
\hline & {$[0.840]$} & {$[0.823]$} & {$[1.034]$} & {$[0.936]$} & {$[10.656]$} & {$[8.976]$} \\
\hline \multirow[t]{2}{*}{ Emerging countries } & -0.592 & -0.875 & 0.675 & 0.343 & $-25.102^{* * *}$ & $-21.559^{* * *}$ \\
\hline & {$[1.196]$} & {$[1.071]$} & {$[1.206]$} & {$[0.927]$} & {$[8.489]$} & {$[7.347]$} \\
\hline \multirow[t]{2}{*}{ Accident $\neq$ listing country } & -0.722 & -0.900 & -1.403 & $-1.549^{*}$ & 8.977 & 5.200 \\
\hline & {$[0.650]$} & {$[0.620]$} & {$[0.885]$} & {$[0.844]$} & {$[7.899]$} & {$[7.188]$} \\
\hline $\mathrm{N}$ & 64 & 64 & 64 & 64 & 64 & 64 \\
\hline Log pseudolikelihood & -124.3 & -125.9 & -141.7 & -142.4 & -253.6 & -256.9 \\
\hline F-stat & $4.2^{* * *}$ & $4.4^{* * *}$ & $7.6^{* * *}$ & $7.9^{* * *}$ & $1.7^{*}$ & $1.9^{* *}$ \\
\hline Adj. R-squared (\%) & 24.5 & 26.6 & 22.0 & 26.3 & 11.3 & 13.3 \\
\hline
\end{tabular}

Note: Robust standard-errors are in brackets: *,**,*** denote statistically significance at the $10 \%$, the $5 \%$ and the $1 \%$ level, respectively. 


\section{Table 8: Determinants of Abnormal Shareholder Losses Following Accidents in the Petro-chemical Industry}

This table reports results from least squares regressions (using White-corrected standard errors). The dependent variable is the Shareholder Loss up to the second day following the disaster: $S L_{i,[0 ;+t]}=C A R_{i,[0 ;+t]} \times M V_{i,-1}$ for $i=1, \ldots, 64$ and $t=1,2$ and where $M V_{i,-1}$ represents the market value on the day before the accident date (in billion dollar). Abnormal returns are computed using the market model. The sample is composed of 64 accidents in the petrochemical industry over the period 1990-2005. Accidents are identified using the software Factiva.

\begin{tabular}{|c|c|c|c|c|}
\hline \multirow[b]{2}{*}{ Model } & $S L_{[0 ;+1]}$ & $L_{[0 ;+1]}$ & $S L_{[0 ;+2]}$ & $S L_{[0 ;+2]}$ \\
\hline & (1) & $(2)$ & (3) & $(4)$ \\
\hline \multirow[t]{2}{*}{ Constant } & $1.281^{*}$ & $0.494^{*}$ & 0.215 & $0.647^{* *}$ \\
\hline & {$[0.652]$} & {$[0.263]$} & {$[0.804]$} & {$[0.273]$} \\
\hline \multirow{2}{*}{ Fatalities and serious injuries } & $-0.104^{* *}$ & $-0.107^{* * *}$ & $-0.167^{* * *}$ & $-0.164^{* * *}$ \\
\hline & {$[0.044]$} & {$[0.039]$} & {$[0.061]$} & {$[0.039]$} \\
\hline \multirow[t]{2}{*}{ Toxic release } & -0.410 & $-0.529^{* *}$ & $-1.142^{*}$ & $-1.005^{* *}$ \\
\hline & {$[0.329]$} & {$[0.260]$} & {$[0.588]$} & {$[0.406]$} \\
\hline \multirow[t]{2}{*}{ \# Previous accidents } & -0.106 & & -0.053 & \\
\hline & {$[0.077]$} & & {$[0.103]$} & \\
\hline \multirow[t]{2}{*}{ Market value $(\$ 2005, \log )$} & -0.083 & & 0.112 & \\
\hline & {$[0.188]$} & & {$[0.181]$} & \\
\hline \multirow[t]{2}{*}{ Abnormal media coverage } & 0.017 & & 0.072 & \\
\hline & {$[0.045]$} & & {$[0.062]$} & \\
\hline \multirow[t]{2}{*}{ Financial press dummy } & -0.067 & & -0.322 & \\
\hline & {$[0.335]$} & & {$[0.485]$} & \\
\hline \multirow[t]{2}{*}{ Chemical industry } & -0.419 & & 0.255 & \\
\hline & {$[0.499]$} & & {$[0.692]$} & \\
\hline \multirow[t]{2}{*}{$1994<$ Accident date $<2000$} & -0.401 & & -0.156 & \\
\hline & {$[0.263]$} & & {$[0.353]$} & \\
\hline \multirow[t]{2}{*}{ Accident date $>1999$} & 0.230 & & 0.084 & \\
\hline & {$[0.428]$} & & {$[0.567]$} & \\
\hline \multirow[t]{2}{*}{ Japan } & -0.410 & -0.400 & -0.269 & -0.208 \\
\hline & {$[0.343]$} & {$[0.243]$} & {$[0.403]$} & {$[0.324]$} \\
\hline \multirow[t]{2}{*}{ Continental Europe } & -0.208 & 0.057 & 0.010 & 0.090 \\
\hline & {$[0.361]$} & {$[0.344]$} & {$[0.521]$} & {$[0.513]$} \\
\hline \multirow[t]{2}{*}{ UK } & 0.771 & 0.788 & 1.141 & $1.137^{* *}$ \\
\hline & {$[0.784]$} & {$[0.600]$} & {$[0.909]$} & {$[0.501]$} \\
\hline \multirow[t]{2}{*}{ Emerging countries } & -2.582 & -2.027 & -0.410 & -0.340 \\
\hline & {$[2.041]$} & {$[1.901]$} & [1.137] & {$[0.731]$} \\
\hline Accident $\neq$ listing country & $\begin{array}{c}-1.332^{* * *} \\
{[0.483]}\end{array}$ & $\begin{array}{l}-1.408^{* * *} \\
{[0.459]}\end{array}$ & $\begin{array}{l}-1.776^{* * *} \\
{[0.646]}\end{array}$ & $\begin{array}{c}-1.637^{* * *} \\
{[0.570]}\end{array}$ \\
\hline $\mathrm{N}$ & 64 & 64 & 64 & 64 \\
\hline Log pseudolikelihood & -97.8 & -101.4 & -109.8 & -111.8 \\
\hline F-stat & $1.6^{*}$ & $2.7^{* * *}$ & $3.1^{* * *}$ & $5.7^{* * *}$ \\
\hline Adj. R-squared (\%) & 29.2 & 30.7 & 24.0 & 29.2 \\
\hline
\end{tabular}

Note: Robust standard-errors are in brackets: *,**, *** denote statistically significance at the $10 \%$, the $5 \%$ and the $1 \%$ level, respectively. 


\section{Notes}

${ }^{1}$ Data are taken from the tenth environmental assessment report of the European Environmental Agency available at http://www. eea.europa.eu/.

${ }^{2}$ See also M.A. White, Investor Response to the Exxon Valdez Oil Spill, Working Paper, University of Virginia Charlottesville (1996).

${ }^{3}$ In Table 1, we also summarize the empirical literature on the stock market response to industrial disasters with environmental consequences.

${ }^{4}$ The results of this literature are not unanimous. [24] show that there is a significant loss when charges are filed, as well as on the settlement day. But, [1] find evidence of significant losses only on the settlement day, while [33] show that abnormal returns are significant only on the filing date. In contrast, [17] and [20], as well as [29] for Canada, do not find significant estimates following lawsuit filing announcements.

${ }^{5}$ In Europe, since the accident of Seveso in Italy in 1976, all firms are obliged to notify accidents to public authorities. In the US, the Environmental Protection Agency provides a complete list of chemical accidents that have occurred in the US since the 1990s. But, due to a principle of commercial confidentiality, the names of companies responsible for accidents are not usually disclosed, at least outside the US. Note that this is all set to change with recent environmental policies aimed at disclosing pollution records (e.g. the $R E A C H$ program for chemicals in the European Union).

${ }^{6}$ We also attempted to proxy the social cost of accidents using the number of nearby residents that were evacuated or warned to stay indoors as a precaution, but information was too limited. 
${ }^{7}$ In principle, environmental risk at the firm level could be proxied by the participation to voluntary initiatives such as the ISO14000 management standard, or the U.S. Global Reporting Initiative (GRI), which provides guidelines for voluntary reporting of environmental and social activities. Unfortunately, these programs were launched at the end of the 1990s.

${ }^{8}$ Recent and notable governmental initiatives include the EU Accounts Modernisation Directive, effective since 2005, which requires EU companies to report information on environmental and employee matters, while private initiatives include the U.S. GRI launched in 1997.

${ }^{9}$ We also considered dummy variables for country of listing, but they were highly correlated. To save space, we do not report the results.

${ }^{10}$ Over the years, insurers have offered comprehensive liability cover for quantifiable damages (such as property damage and bodily injury), but they are still not able to offer coverage for purely ecological damage (see [13] and Swiss Re, The Economics of Liability Losses - Insuring a Moving target, Sigma No 6/2004). Besides, the market for incidental pollution insurance is small (the total premium income for the US environmental insurance market was US $\$ 1$ billion in 2006, according to Munich Re).

${ }^{11}$ The event-study methodology is widely used in finance. For instance, [28] list more than 565 event studies (dealing with shares distributions, earnings and/or dividends, mergers, massive layoffs, etc.) published between 1974 and 2000 in the five leading finance journals. The number of papers per year increased in the 1980's and has been quite stable since then.

${ }^{12}$ To check for robustness, we dropped the accidents when the parameter $\widehat{\beta}_{i}$ is not significant. It does not change the results.

${ }^{13}$ Another measure of significance aggregates, into a single portfolio, the abnormal returns of 
all petrochemical companies experiencing an accident for the day of each firm's explosion. It then uses the daily variance of returns on this portfolio to calculate a t-statistic. This test, however, attributes more weight to observations of firms with a high variance in returns, and is therefore more sensitive to distortions from very noisy observations.

${ }^{14}$ Cumulative abnormal returns $\left(C A R_{i, t}\right)$ are reported for each accident $(i)$ in Table 4.

${ }^{15}$ In unreported results, we computed cumulative average abnormal returns using different event window lengths. Results confirm that no abnormal losses are detected shortly before the disaster, so that the event window is well specified on average. Moreover, we also examined whether the price pressure was associated with a significant shift in trading volumes. We defined abnormal volume as the difference between the average turnover ratio logarithm through the period $[-190 ;-10]$ and the observed turnover ratio logarithm after the disaster. We found that abnormal trading volumes are of $9 \%$ on average on the accident day, but not statistically significant from zero.

${ }^{16}$ This interpretation is in line with [40] who shows that investors react only gradually to news announcements when information is more uncertain.

${ }^{17}$ Conversely, for less serious accidents, when looking at a longer event window, we expect subsequent cumulative abnormal returns to remain unchanged or to be gradually overwhelmed by additional news announcements.

${ }^{18}$ The previous empirical literature on the stock market response to industrial disasters with environmental consequences (including nuclear accidents) is also summarized in Table 1.

${ }^{19}$ The author does not provide any dollar-value estimation.

${ }^{20}$ Notice that the paper by [20] only provides results for the entire sample. To make their 
analysis comparable to ours, the average abnormal return was computed by considering the pollution accidents only.

${ }^{21} \mathrm{~A}$ few studies have also looked at nuclear accidents. [6], and [19] look at the stock market reaction to the Three Mile Island accident, while [22] and [12] examine the Chernobyl nuclear meltdown. Results from these studies are summarized in Table 1.

${ }^{22}$ See M.A. White, Investor Response to the Exxon Valdez Oil Spill, Working Paper, University of Virginia Charlottesville (1996).

${ }^{23}$ According to data provided by Swiss Re (see its website, www. swissre.com), the total insured losses per year for man-made disasters (which includes fires and explosions, aviation disasters, collapse of buildings/bridges, etc.) has more than tripled from 1970 to 2008 . At the same time, the number of man-made disasters covered by insurance has almost tripled. Moreover, big petrochemical firms have created captive insurance companies to cover industrial risk.

${ }^{24}$ We also built a variable for the number of minor injuries (i.e., all injuries that are not reported as serious), but this variable does not change the results.

${ }^{25}$ Our estimates are greater than those obtained by the labor literature that uses data on wages in risky jobs to infer the implicit value of life. For example, in [38] the estimated value of one life falls between $\$ 3$ and $\$ 9$ million. This is not surprising given that the number of fatalities proxies for a wide range of uninsured costs (reduced productivity, insurance premiums, compensation claims, damaged reputation, legal implications and punitive damages). 